\title{
Correction to: SentimagIC: A Non-inferiority Trial Comparing Superparamagnetic Iron Oxide Versus Technetium-99m and Blue Dye in the Detection of Axillary Sentinel Nodes in Patients with Early-Stage Breast Cancer
}

\author{
Michael D. Alvarado, $\mathrm{MD}^{1}$, Elizabeth A. Mittendorf, $\mathrm{MD}^{2}$, Mediget Teshome, $\mathrm{MD}^{2}$, Alastair M. Thompson, $\mathrm{MD}^{2}$, \\ Richard J. Bold, $\mathrm{MD}^{3}$, Mark A. Gittleman, $\mathrm{MD}^{4}$, Peter D. Beitsch, $\mathrm{MD}^{5}$, Sarah L. Blair, MD ${ }^{6}$, \\ Kaisa Kivilaid, $\mathrm{MS}^{7}$, Quentin J. Harmer, $\mathbf{P h D}^{8}$, and Kelly K. Hunt, $\mathrm{MD}^{2}$ \\ ${ }^{1}$ Department of Surgery, University of California San Francisco, San Francisco, CA; ${ }^{2}$ Department of Breast Surgical \\ Oncology, The University of Texas MD Anderson Cancer Center, Houston, TX; ${ }^{3}$ Division of Surgical Oncology, \\ Department of Surgery, UC Davis Medical Center, Sacramento, CA; ${ }^{4}$ Breastcare Specialists, Allentown, PA; ${ }^{5}$ Dallas \\ Surgical Group, Dallas, TX; ${ }^{6}$ Department of Surgery, Moores Cancer Center, University of California San Diego, La Jolla, \\ $\mathrm{CA} ;{ }^{7}$ Regulatory and Clinical Research Institute, Inc., Minneapolis, MN; ${ }^{8}$ Endomagnetics Limited, Cambridge, UK
}

\section{CORRECTION TO:}

ANN SURG ONCOL (2019) 26:3510-3516

HTTPS://DOI.ORG/10.1245/S10434-019-07577-4

In the original article the authors' disclosures were incomplete. Following is the revised text:
This clinical study was sponsored by Endomagnetics Inc., which provided funding to the institutions of all authors (K. Hunt PI). Dr. Michael D. Alvarado received travel support from Endomagnetics Inc. All other authors reported no conflicts of interest.

Publisher's Note Springer Nature remains neutral with regard to jurisdictional claims in published maps and institutional affiliations.

The original article can be found online at https://doi.org/10.1245/ s10434-019-07577-4.

(C) Society of Surgical Oncology 2020

Published Online: 8 June 2020

M. D. Alvarado, MD

e-mail: michael.alvarado@ucsf.edu 